\title{
Deafness-ear malformation-facial palsy syndrome
}

INSERM

\section{Source}

INSERM. (1999). Orphanet: an online rare disease and orphan drug data base. Deafnessear malformation-facial palsy syndrome. ORPHA:3232

Deafness-ear malformation-facial palsy syndrome is characterized by profound conductive deafness due to stapedial abnormalities associated with variable malformations of the external ears and facial paralysis. It has been described in three sibs and their mother. Inheritance is autosomal dominant. 